\title{
ANTIOXIDANT AND ANTICANCER POTENTIALS OF BIOFABRICATED SILVER NANOPARTICLES
}

\author{
MERINA PAUL DAS*, L JEYANTHI REBECCA
}

Department of Industrial Biotechnology, Bharath University, Chennai, Tamil Nadu, India. Email: merinadas@gmail.com

Received: 21 June 2016, Revised and Accepted: 09 September 2017

\begin{abstract}
Objective: The objective of this study is to explore a rapid, bio-inspired approach to synthesize silver nanoparticles (AgNPs) using aqueous Nardostachys jatamansi leaf extract and evaluate its antioxidant and cytotoxic activities on human colon carcinoma (HCT-116) cell lines.

Methods: The biosynthesized nanoparticles were analyzed using ultraviolet-visible spectrophotometer, scanning electron microscope (SEM), energy dispersive X-ray, X-ray diffractometer (XRD), and Fourier transform infrared spectroscopy. Free radical scavenging and cytotoxic studies were carried out at different concentrations of AgNPs (20-100 $\mu \mathrm{g} / \mathrm{mL})$ using antioxidant 2,2-diphenyl-1-picrylhydrazil (DPPH) and mitochondrial function assay methods.

Results: Surface plasmon resonance spectrum at $434 \mathrm{~nm}$ confirmed the formation of AgNPs. SEM images show biosynthesized AgNPs are mostly spherical shaped within the range of 30.0-58.7 nm. XRD analysis reveals the crystallographic face-centered cubic structure of the AgNPs. Thus, synthesized metal nanoparticles were tested for antioxidant activity by DPPH assay, and anticancer activity was validated by lactate dehydrogenase leakage assay. Significant antioxidant property was observed as compared to standard L-ascorbic acid. Further, AgNPs showed a linear dose-response relationship against HCT-116 cell lines with increasing concentration of AgNPs. At a concentration of $20 \mu \mathrm{g} / \mathrm{mL}$, AgNPs were able to inhibit the cell line's growth by less than $9.8 \pm 0.7 \%$, whereas $100 \mu \mathrm{g} / \mathrm{mL}$ of AgNPs significantly inhibited the cell line's growth greater than $90.4 \pm 0.25 \%$
\end{abstract}

Conclusion: The synthesized AgNPs were found to be highly stable and had significant antioxidant and anticancer activity against HCT-116 cell lines. It has wide applications in the biomedical field and can be produced with eco-friendly, rapid scale-up, and easy downstream processing

Keywords: Nardostachys jatamansi, Approach to synthesize silver nanoparticles, Characterization, Antioxidant, Cytotoxicity.

(C) 2017 The Authors. Published by Innovare Academic Sciences Pvt Ltd. This is an open access article under the CC BY license (http://creativecommons. org/licenses/by/4. 0/) DOI: http://dx.doi.org/10.22159/ajpcr.2017.v10i12.20878

\section{INTRODUCTION}

In the last decades, nanotechnology-based products have come up with a wide spectrum of applications in the field of optoelectronics, lithography, photography, biomedicals, etc. [1-3]. The success of nanotechnology largely relies on engineered nanomaterials due to their extensive physicochemical properties such as composition, controlled shape and size, morphology, high surface to volume ratio, and stability. Conventionally, various physical and chemical methods [4-7] such as thermal evaporation [8,9], photochemical reduction [10], electrochemical reduction [11,12], and sonochemistry methods are regularly used to synthesize the nanomaterials. Adversely, overexploitation of nanomaterials causes a serious threat in the environment and water bodies. During synthesis, various hazardous chemicals, such as SDS, haxamine, $\beta$-mercaptanol and their by-products are exposed to the biotic and abiotic systems [13]. Alternatively, rapid, cost-effective and eco-friendly approach has been proved to be an alternative way to synthesize bionanomaterials.

Recently, various types of microorganisms including fungi and bacteria, animal cells, and different parts of the plant such as stem, leaf, bark, and fruit have been reported for development of inorganic metal nanomaterials. The advantages of using plant biomaterial for the biosynthesis of nanoparticles over other biological methods are to eliminate the elaborate cell culture techniques, maintenance of aseptic condition, scale up easily, and reduce the overall production cost [14]. So far, biogenic synthesis of $\mathrm{Ag}, \mathrm{Au}, \mathrm{Pd}, \mathrm{Pt}, \mathrm{ZnO}, \mathrm{CuO}, \mathrm{MgO}, \mathrm{SiO}_{2}$, and $\mathrm{Fe}_{2} \mathrm{O}_{3}$ [15] nanoparticles have already been documented. Among the nanoparticles, approach to synthesize silver nanoparticles (AgNPs) gained significant attention due to their diverse application particularly in the field of (i) biomedical (antimicrobial agent for (a) wound and burn healing, (b) textile industries, (c) food industries, (d) cosmetic industries, and anticancer agent in controlled drug delivery system), (ii) sensing technology to fabricate the sensor due to its conductive properties and used for detection of various inorganic metals, and biomolecules, (iii) electronics to fabricate microchips, and (iv) catalysis for degrading hazardous dyes and removal of toxic metal ions from the pollutants [16]. In recent years, green chemistry based bio-reduction of silver ions were well-adapted methods in the scientific community. Till date, several plants such as Wedelia chinensis [17], Digitaria radicosa [18], Catharanthus roseus [19], and Allium sativum [20] were documented for the synthesis of AgNPs.

In this study, we report the bioreduction and stabilization of silver nanoparticles using Nardostachys jatamansi leaf. $N$. jatamansi is belonging to Valerianaceae family; it is a small, hairy, perennial, erect, and rhizomatous herb. Phytochemical screening has revealed that it contained a large amount of bioactive compounds such as alkaloids, sesquiterpenes, lignans, coumarins, and steroids that are used for medicinal purposes [21,22]. This plant is appreciated for its antioxidant, antibacterial, stimulant, sedative, antifungal, antidiabetic, neuroprotective, hepatoprotective, anticancer, and cardioprotective properties [23-25]. This investigation aimed to discuss about unreported bio-based synthesis of AgNPs using leaf extract of $N$. jatamansi and the antioxidant and anticancer properties of synthesized nanoparticles were evaluated.

\section{MATERIALS AND METHODS}

\section{Chemicals}

All the chemicals were purchased from HiMedia (India) with a high degree of purity. All reagents were used as supplied. Sterile distilled water was used throughout the experiments. 
Biosynthesis of silver nanoparticles

Fresh leaves of $N$. jatamansi were collected, washed thoroughly with distilled water, shade dried for $5 \mathrm{~d}$ and powdered. $5 \mathrm{~g}$ of leaf powder was mixed with $100 \mathrm{~mL}$ of distilled water and boiled at $60^{\circ} \mathrm{C}$ for 15 minutes. The mixture was then cooled and filtered through Whatman No. 1 filter paper. About $10 \mathrm{~mL}$ of this extract was added dropwise in $90 \mathrm{~mL}$ of $1 \mathrm{mM}$ aqueous silver nitrate $\left(\mathrm{AgNO}_{3}\right)$ solution, and the color of the solution changed to brown. The appearance of color indicated the formation of silver nanoparticles. The resulting suspension was centrifuged and purified AgNPs were used for further analysis.

\section{Characterization of biogenic AgNPs}

The reduction of silver ion and formation of AgNPs were confirmed by scanning the absorbance using ultraviolet-visible (UV-vis) spectrophotometer between 200 and $700 \mathrm{~nm}$. The size and morphology were monitored using scanning electron microscope (SEM), and the purity of the sample was examined by energy dispersive X-ray (EDX) attached with SEM. Further biomolecules involved in the bioreduction of silver ions were examined using Fourier transform infrared spectroscopy (FTIR) spectroscopy within the range of $400-4000 / \mathrm{cm}$ at a resolution of $4 / \mathrm{cm}$. X-ray diffractometer (XRD) pattern of synthesized AgNPs was performed on an XRD, at a voltage of $45 \mathrm{kV}$ and a current of $40 \mathrm{~mA}$ with $\mathrm{Cu} \mathrm{K} \alpha$ radiation to study the crystalline nature of the nanoparticles.

\section{Antioxidant assay}

The antioxidant activity of AgNPs was determined by 2,2-diphenyl1-picrylhydrazil (DPPH) free radical scavenging assay spectrophotometrically [26]. In brief, different concentrations of AgNPs $(20-100 \mu \mathrm{g} / \mathrm{mL})$ were added to $0.3 \mathrm{mM}$ of methanolic solution of DPPH and allowed to react for 30 minutes. Then, the decrease in absorbance (A) was measured at $517 \mathrm{~nm}$ against methanol as control and ascorbic acid (AA) as standard. Percentage of free radical scavenging activity was calculated using the equation 1 .

$$
\text { DPPH scavenging activity }(\%)=\frac{\text { A Control }- \text { A Sample }}{\text { A Control }} \times 100
$$

\section{Cell viability assay}

The cell viability assay of the biogenic AgNPs was determined by mitochondrial function (MTT) [3-(4,5-dimethylthiazole-2-yl)-2,5diphenyltetrazolium] test against human colon carcinoma cell lines (HCT-116) [27]. This test analyses the MTT of viable cells to reduce MTT into purple formazon product. Briefly, cancer cell density of $1 \times 10^{6}$ cells $/ \mathrm{mL}$ was seeded into 96 well plates and treated with different concentrations of AgNPs $(20-100 \mu \mathrm{g} / \mathrm{mL})$ and incubated at the $\mathrm{CO}_{2}$ incubator for $48 \mathrm{hrs}$. After incubation, cells were washed with PBS (phosphate-buffered saline) to remove dead cells, treated with $200 \mu \mathrm{L}$ of MTT and incubated for $5 \mathrm{hrs}$ in the $\mathrm{CO}_{2}$ incubator until purple precipitate appears. Further, $100 \mu \mathrm{L}$ of DMSO (dimethyl sulfoxide) was added to dissolve the purple formazan product and absorbance was taken at $595 \mathrm{~nm}$ in a microplate reader. Percentage of cell viability was calculated using the equation 2.

$\%$ of cell viability $=\frac{\text { Absorbance of experimental sample (AgNPs) }}{\text { Absorbance of control (untreated) }} \times 100$

\section{Lactate dehydrogenase (LDH) leakage assay}

When cell membrane gets effected, cytoplasmic LDH releases into the media and the concentration of LDH increased in extracellular media. AgNPs stimulate cytotoxicity, results damaging the cell membrane causing cell death. Thus, amount of LDH leakage from damaged colon carcinoma cells HCT-116 was measured by LDH cytotoxicity assay kit (Sigma-Aldrich). In brief, cells were exposed to different concentrations of AgNPs $(20-100 \mu \mathrm{g} / \mathrm{mL})$ for $48 \mathrm{hrs}$. After the treatment, cell-free supernatant was mixed with $100 \mu \mathrm{L}$ of LDH assay buffer and incubated for 30 minutes. The absorbance of the solution was measured at $490 \mathrm{~nm}$ using a microplate reader. These data were normalized to the activity of LDH released from treated cells and expressed as a percentage of the control.

\section{RESULTS AND DISCUSSION}

Usually, the performance of the nanoparticles largely depends on its size, shape, and homogeneity. When $N$. jatamansi leaf extract (NLE) was mixed with warm silver nitrate $(1 \mathrm{mM})$ solution, the resulting solution observed to change color from colorless to brown after 30 minutes of reaction; the preliminary study confirmed the bioreduction and synthesis of AgNPs. As the reaction proceeds, the color intensity of the resulting mixture increases with increasing reaction time. This may be due to the surface plasmon resonance (SPR) of the AgNPs, which is characterized by UV-vis spectra depending on its size and shape. The biochemical reaction of the leaf extract and $\mathrm{Ag}^{+}$was confirmed by recording the UV-vis spectra. Fig. 1 shows the strong SPR band at $432 \mathrm{~nm}$ confirming the formation of AgNPs [28]. The presence of single absorption peak indicates the uniform size and spherical shape of nanoparticles [29].

SEM has been used to observe the size, shape, and morphology of metal nanoparticles using a secondary electron detector. SEM micrograph reveals the roughly spherical shaped particles in the average size ranged between 30.0 and $58.7 \mathrm{~nm}$ (Fig. 2a). The particles were found aggregated, and it might be due to the presence of high concentration of plant extract. Further, the presence of elemental silver was confirmed by EDX analysis. EDX spectrum (Fig. 2b) of biosynthesized AgNPs exhibited a strong signal of silver with the addition of chlorine and oxygen. The crystallinity of AgNPs was confirmed by the dominant and sharp signal at $3 \mathrm{KeV}$ due to SPR vibration [30]. The result indicates the conversion of silver ions to elemental silver. Along with $\mathrm{Ag}$ band, additional $\mathrm{Cl}$ and 0 peaks were also observed due to the stabilizing biomolecules present in AgNPs, associated during the synthesis of nanoparticles.

FTIR spectrum illustrates the role of the various functional groups present in NLE involved in biosynthesis reaction. Fig. 3 shows a number of IR bands at $648,1086,1438,1626,2994$, and $3372 / \mathrm{cm}$, indicating the complexity of lyophilized NLE mediated AgNPs. The strong peaks were observed at 1086 for $-\mathrm{C}-\mathrm{O}-\mathrm{C}-$ or $-\mathrm{C}-\mathrm{O}-$ stretch, $1626 / \mathrm{cm}$ due to $\mathrm{C}=\mathrm{C}$ aromatic stretching, and $3372 / \mathrm{cm}$ is due to free $\mathrm{O}-\mathrm{H}$ vibrations [31]. The distinct bands at 1438 and $2994 / \mathrm{cm}$ were assigned for methylene scissoring vibrations and $\mathrm{C}-\mathrm{H}$ stretching vibrations, respectively. These functional groups are present in water-soluble fractions of NLE, e.g., alkaloids, flavonoids, and terpenoids. These biomolecules might be responsible for the reduction of silver ions and stabilization of biosynthesized AgNPs using leaves of $N$. jatamansi. Fig. 4 shows the XRD pattern of biosynthesized AgNPs using NLE. XRD analysis showed intense peaks at $2 \theta$ values of $38.13^{\circ}, 45.08^{\circ}, 63.5^{\circ}$, and $77.21^{\circ}$

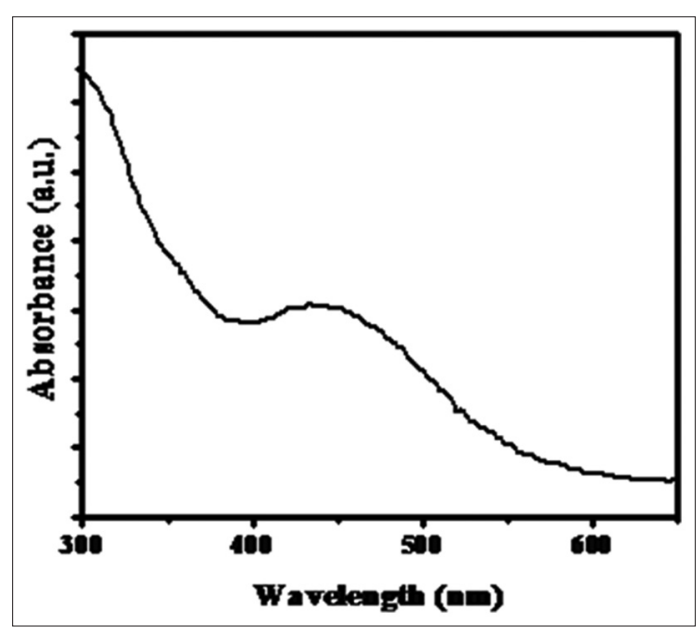

Fig. 1: Ultraviolet-visible spectrum of silver nanoparticles 
corresponding to (111), (200), (220), and (311) sets of lattice planes, respectively. These bands suggest that AgNPs are face-centered cubic crystalline structure, the same result was also found by Wilson et al. [32]. Average crystal size of the synthesized AgNPs was determined applying Debye-Scherrer equation and is found to be $37.82 \mathrm{~nm}$.

The antioxidant activity of the synthesized AgNPs was studied by DPPH radical scavenging assay and compared with AA as standard. Free radicals such as reactive oxygen species and reactive nitrogen

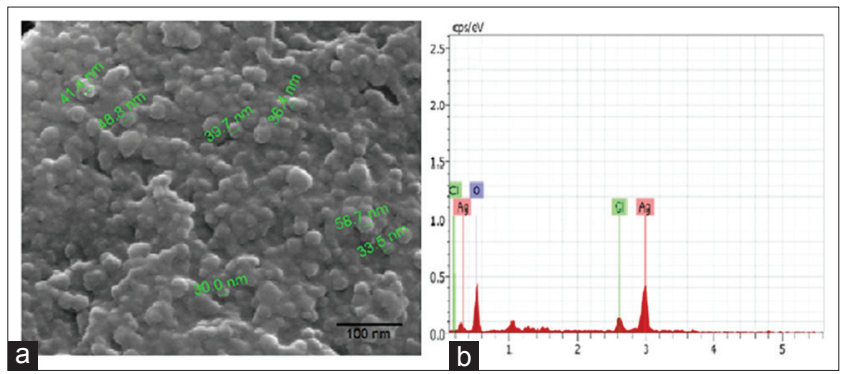

Fig. 2: (a) Scanning electron microscope micrograph of approach to synthesize silver nanoparticles and (b) corresponding energy dispersive X-ray spectrum

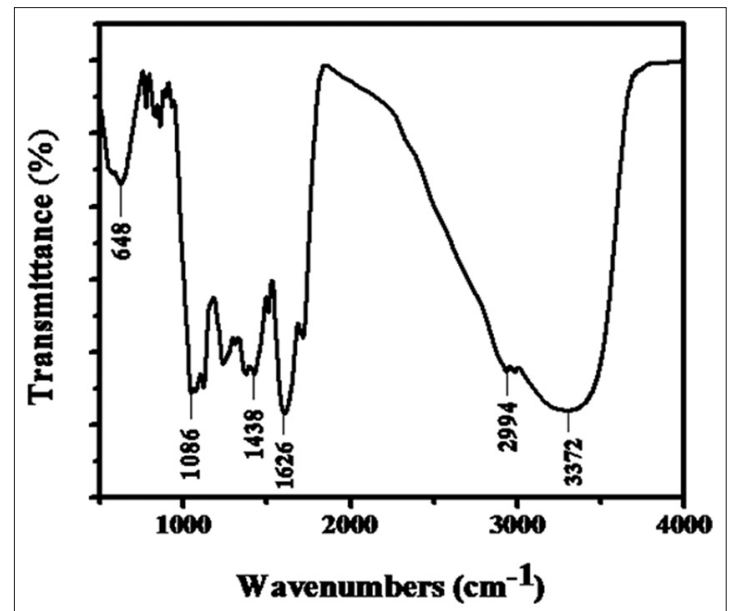

Fig. 3: Fourier transform infrared spectroscopy spectrum of silver nanoparticles

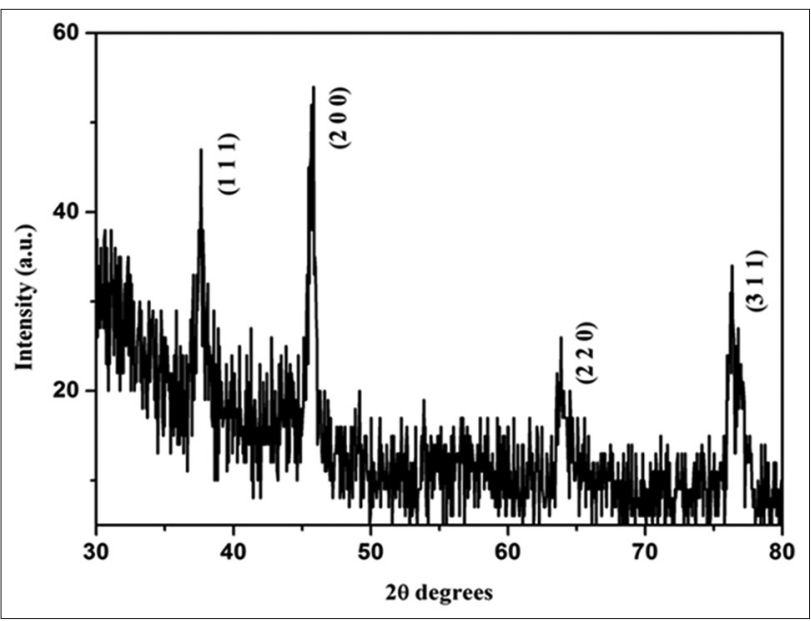

Fig. 4: X-ray diffraction pattern of approach to synthesize silver nanoparticles synthesized using Nardostachys jatamansi leaf extract species generations by cells are normal physiological activity. Excessive formation of these radicals in human body causes cell damage by combining with the biomolecules, such as protein, carbohydrates, lipids, and finally leading to various diseases, such as cancer, coronary heart disease, aging, neurodegenerative disorders, and diabetes. [33]. Antioxidants play a significant role to control such oxidative stress situation by neutralizing these reactive radicals. Fig. 5 illustrates DPPH scavenging activity proportionately increasing with an increase in the concentration of AgNPs. Purple color solution of DPPH converted to colorless product in the presence of nanoparticles, causing a decrease in absorbance. Rapid reduction in absorbance indicates the potential activity of antioxidants. AgNPs showed an effective free radical scavenging activity of $87 \pm 0.13 \%$ at the nanoparticle concentration $100 \mu \mathrm{g} / \mathrm{mL}$, whereas the standard L-AA showed $93 \pm 0.2 \%$ of scavenging activity at the same concentration. The similar antioxidant property was also found for nanoparticles synthesized from D. radicosa leaf, Helicteres isora root extract [18,34].

The anticancer property of AgNPs against cell lines (HCT-116) was studied using cell viability assay. Cell viability assay was carried out by performing the MTT test and reconfirmed by LDH assay. The transformed cells were exposed with different concentrations of AgNPs (20-100 $\mu \mathrm{g} / \mathrm{mL})$ for $48 \mathrm{hrs}$. Fig. 6 a shows the cell viability which decreased linearly with increased in nanoparticles concentration. The AgNPs were potentially cytotoxic to HCT-116 cells at $100 \mu \mathrm{g} / \mathrm{mL}$ with cell viabilities of $9.6 \pm 0.12 \%$. The cytotoxicity of AgNPs induces the inactivation of DNA replication, causing enzyme inhibition, resulting in loss of cell viability and finally leading to cell death [35]. This result was strongly supported by LDH assay. It measures the amount of cellular LDH enzyme released due to cell membrane damage. Thus, a similar dose-dependent pattern was observed in LDH leakage after cells were

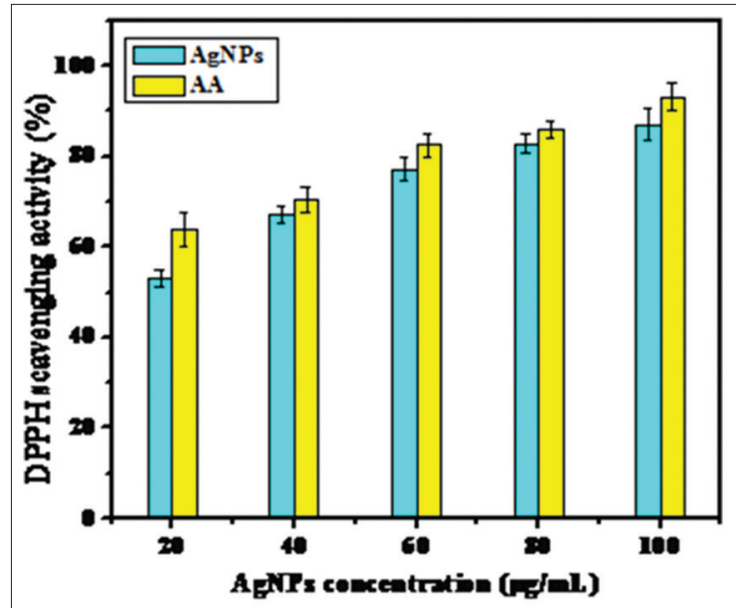

Fig. 5: 2,2-diphenyl-1-picrylhydrazil free radical scavenging activity of biogenic approach to synthesize silver nanoparticles and standard L-ascorbic acid

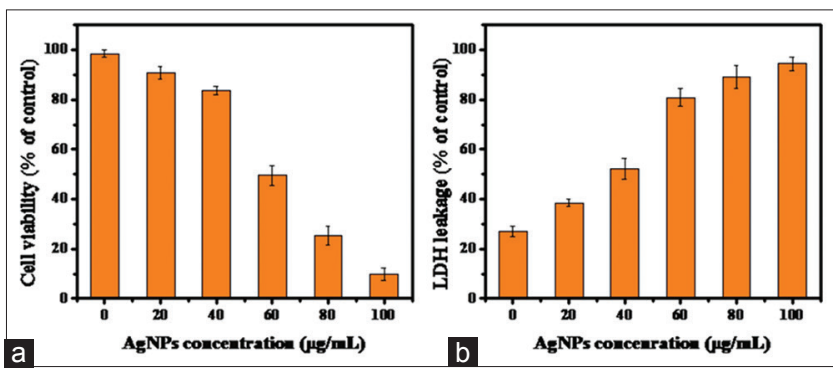

Fig. 6: (a) Cytotoxic effect of approach to synthesize silver nanoparticles (AgNPs) on cancer cell line human colon carcinoma and (b) effect of AgNPs in lactate dehydrogenase leakage 
treated with different concentrations of AgNPs for 48 hrs (Fig. 6b). The HCT-116 cells incubated with $100 \mu \mathrm{g} / \mathrm{mL}$ showed the significant LDH leakage $(94.8 \pm 0.33 \%)$ in the cell culture supernatant, which is a sensitive indicator of cell damage and cytotoxicity. The biosynthesized AgNPs exhibit significant anticancer activity against cancer cell lines based on increasing nanoparticles concentration was reported in some studies [36]. This result suggests that AgNPs may be used as effective nano-medicine for the anticancerous drug formulations.

\section{CONCLUSION}

The present research demonstrates an eco-friendly and rapid synthesis of silver nanoparticles through a green chemistry route. In this attempt, NLE was used to synthesize stable AgNPs in room temperature. The NLE derived spherical AgNPs exhibited significant antioxidant and anticancer properties. Results suggest that AgNPs may be used as a potent anti-proliferative candidate on HCT cells. Further thorough research is required to evaluate the molecular mechanism behind these effects of AgNPs and thereby permitting this biofabricated AgNPs as cancer chemopreventive drug in the human body.

\section{ACKNOWLEDGEMENT}

The authors convey their thanks to the Department of Industrial Biotechnology, Bharath University, Chennai, for providing laboratory facilities. The author also acknowledges SRM University, Chennai, for providing support in carrying out SEM, and IIT, Chennai, for FTIR and XRD analysis.

\section{REFERENCES}

1. Smith AM, Duan H, Rhyner MN, Ruan G, Nie SA. Synthesis of gold nanoparticles bearing the bio conjugation. Phys Chem Chem Phys 2006;8:3895-903.

2. Kearns GJ, Foster EW, Hutchison JE. Substrates for direct imaging of chemically functionalized $\mathrm{SiO}_{2}$ surfaces by transmission electron microscopy. Anal Chem 2006;78(1):298-303.

3. Sarkar S, Jana AD, Samanta SK, Mostafa G. Facile synthesis of silver nanoparticles with highly efficient anti-microbial property. Polyhedron 2007:26:4419-26

4. Yu DG. Formation of colloidal silver nanoparticles stabilized by $\mathrm{Na}^{+}$-poly (gamma-glutamic acid)-silver nitrate complex via chemical reduction process. Colloids Surf B Biointerfaces 2007;59(2):171-8.

5. Tan Y, Wang Y, Jiang L, Zhu D. Thiosalicylic acid-functionalized silver nanoparticles synthesized in one-phase system. J Colloid Interface Sci 2002;249(2):336-45.

6. Petit C, Lixon P, Pileni MP. In situ synthesis of silver nanocluster in AOT reverse micelles. J Phys Chem 1993;97(49):12974-83.

7. Vorobyova SA, Lesnikovich AI, Sobal NS. Preparation of silver nanoparticles by interphase reduction. Colloids Surf A 1999;152:375-9.

8. Bae $\mathrm{CH}$, Nam SH, Park SM. Aluminium nanoparticles production by laser ablation in liquids. Appl Surf Sci 2002;197:628-34.

9. Smetana AB, Klabunde KJ, Sorensen CM Synthesis of spherical silver nanoparticles by digestive ripening, stabilization with various agents, and their 3-D and 2-D superlattice formation. J Colloid Interface Sci 2005;284(2):521-6.

10. Mallick K, Witcombb MJ, Scurrella MS. Self-assembly of silver nanoparticles in a polymer solvent: Formation of a nano chain through nano scale soldering. Mater Chem Phys 2005;90:221-4.

11. Liu YC, Lin LH. New pathway for the synthesis of ultrafine silver nanoparticles from bulk silver substrates in aqueous solutions by son electrochemical methods. Electrochem Commun 2004;6(11):1163-8.

12. Sandmann G, Dietz H, Plieth W. Preparation of silver nanoparticles on ITO surfaces by a double-pulse method. Electroanal Chem 2000;491(1-2):78-86.

13. Saxena A, Tripathi RM, Singh RP. Biological synthesis of silver nanoparticles by using onion (Allium cepa) extract and their antibacterial activity. Dig J Nanomater Bios 2010;5(2):427-32.

14. Rajakumar G, Rahuman AA. Larvicidal activity of synthesized silver nanoparticles using Eclipta prostrata leaf extract against filariasis and malaria vectors. Acta Trop 2011;118(3):196-203.

15. Sharma D, Kanchi S, Bisetty K. Biogenic synthesis of nanoparticles: A review. Arabian J Chem 2015;7:1131-9.

16. Vishnu AV, Subhash N, Shakilabanu A, Kurian GA. Characterization and biological evaluation of silver nanoparticles synthesized by aqueous root extract of Desmodium gangeticum for its antioxidant, antimicrobial and cytotoxicity. Int J Pharm Pharm Sci 2014;7 Suppl 1:182-6.

17. Das MP, Rebecca JL, Veluswamy P, Das J. Exploration of Wedelia chinensis leaf-assisted silver nanoparticles for antioxidant, antibacterial and in vitro cytotoxic applications. J Food Drug Anal 2017;157:1801-8.

18. Kalaiyarasu T, Karthi N, Gowri VS, Manju V. In vitro assessment of antioxidant and antibacterial activity of green synthesized silver nanoparticles from Digitaria radicosa leaves. Asian J Pharm Clin Res 2016;9(1):297-302.

19. Subha V, Ravindran RS, Hariram J, Renganathan S. Bioreduction of silver nanoparticles from aqueous stem extract of Catharanthus roseus and bactericidal effects. Asian J Pharm Clin Res 2015;8(5):115-8.

20. Rastogi L, Arunachalam J. Sunlight based irradiation strategy for rapid green synthesis of highly stable silver nanoparticles using aqueous garlic (Allium sativum) extract and their antibacterial potential. Mater Chem Phys 2011;129:558-63.

21. Rekha K, Rao RR, Pandey R, Prasad KR, Babu KS, Vangala JR, et al. Two new sesquiterpenoids from the rhizomes of Nardostachys jatamansi. J Asian Nat Prod Res 2013;15(2):111-6.

22. Singh A. Herbalism, Photochemistry and Ethno Pharmacology. Boca Raton: CRC Press; 2011.

23. Khan MB, Hoda MN, Ishrat T, Ahmad S, Moshahid Khan M, Ahmad A, et al. Neuroprotective efficacy of Nardostachys jatamansi and crocetin in conjunction with selenium in cognitive impairment. Neurol Sci 2012;33(5):1011-20.

24. Chaudhary S, Chandrashekar KS, Pai KS, Setty MM, Devkar RA, Reddy ND, et al. Evaluation of antioxidant and anticancer activity of extract and fractions of Nardostachys jatamansi DC in breast carcinoma. BMC Complement Altern Med 2015;15:50.

25. Purnima MB, Kothiyal P. A review article on photochemistry and pharmacological profiles of Nardostachys jatamansi DC medicinal herb. J Pharmacogn Phytochem 2015;3(5):102-6.

26. Hu F, Lu R, Huang B, Liang M. Free radical scavenging activity of extracts prepared from fresh leaves of selected Chinese medicinal plants. Fitoterapia 2004;75(1):14-23.

27. Vivek R, Kannan S, Achiraman S, Thirumurugan R, Ganesh DS, Krishnan M. Survivin deficiency leads to imparalization of cytokinesis in cancer cells. Asian Pac J Cancer Prev 2011;12(7):1675-9.

28. Kirthika P, Dheeba B, Sivakumar R, Abdulla SS. Plant mediated synthesis and characterization of silver nanoparticles. Int J Pharm Pharm Sci 2014;6:304-10.

29. Ramalingam V, Rajaram R, Kumar CP, Santhanam P, Dhinesh P, Vinothkumar S, et al. Biosynthesis of silver nanoparticles from deep sea bacterium Pseudomonas aeruginosa JQ989348 for antimicrobial, ant biofilm, and cytotoxic activity. J Basic Microbiol 2014:54(9):928-36.

30. Muthukrishnan S, Bhakya S, Kumar TS, Rao MV. Biosynthesis, characterization and antibacterial effect of plant-mediated silver nanoparticles using Ceropegia thwaitesii-an endemic species. Ind Crops Prod 2015;63:119-24.

31. Wang ZM, He XX, Sun DQ. Practical Infrared Spectroscopy. Beijing: Petroleum Industry Press; 1982. p. 164-6.

32. Wilson A, Prabukumar S, Sathishkumar G, Sivaramakrishnan S. Aspergillus flavus mediated silver nanoparticles synthesis and evaluation of its antimicrobial activity against different human pathogens. Int J App Pharm 2016;8(4):43-6.

33. Wu D, Cederbaum AI. Alcohol, oxidative stress, and free radical damage. Alcohol Res Health 2003;27(4):277-84.

34. Bhakya S, Muthukrishnan S, Sukumaran M, Muthukumar M. Biogenic synthesis of silver nanoparticles and their antioxidant and antibacterial activity. Appl Nanosci 2016;6:755-66.

35. Gogoi SK, Gopinath P, Paul A, Ramesh A, Ghosh SS, Chattopadhyay A. Green fluorescent protein-expressing Escherichia coli as a model system for investigating the antimicrobial activities of silver nanoparticles. Langmuir 2006;22(22):9322-8.

36. Suganya G, Karthi S, Shivakumar MS. Larvicidal potential of silver nanoparticles synthesized from Leucas aspera leaf extracts against dengue vector Aedes aegypti. Parasitol Res 2014;113(3):875-80. 